to $32 \mathrm{~g}$ ) per capita/day. Similar trends are observed across the three socio-economic groups.

We note a decline in energy purchased from meat and fish (8 kcal), bread and cereals $(21 \mathrm{kcal})$, and fruits and vegetables (9 kcal), but an increase in the calories from dairy $(7 \mathrm{kcal})$ and savoury snacks $(9 \mathrm{kcal})$. There is a decrease in the energy and sugar purchased from less healthy non-alcoholic drinks, such that purchases of energy and sugar from healthier alternatives now exceed in comparison.

The nutritional content of sweet snacks expenditure has not changed (197 kcal and $18 \mathrm{~g}$ of sugar per capita/day). In contrast, the energy and sugar purchased from desserts and puddings decreased from $195 \mathrm{kcal}$ (95\% CI 194 to $196 \mathrm{kcal}$ ) to $166 \mathrm{kcal}$ (95\% CI 165 to $167 \mathrm{kcal})$, and from $20 \mathrm{~g}$ (95\% CI 20 to $20 \mathrm{~g})$ to $17 \mathrm{~g}(95 \% \mathrm{CI} 16$ to $17 \mathrm{~g})$ respectively, accounting for $46 \%$ percent of the total decrease in sugar purchased daily.

Conclusion While small improvements in the nutritional content of food purchased for at-home consumption are detected, these may be offset by different trends in out-of-home purchases. To understand the extent to which these improvements influence social inequalities, further analyses focus on socioeconomic differences in the nutritional content of purchases across all the food groups over time.

\section{Cardiovascular disease}

\section{OP42 POTENTIAL IMPACTS OF BREXIT ON CARDIOVASCULAR DISEASE VIA CHANGES TO THE PRICE OF FRUITS AND VEGETABLES: A MODELLING ANALYSIS}

${ }^{1} S$ Seferidi ${ }^{*},{ }^{1} \mathrm{AA}$ Laverty, ${ }^{1,2} \mathrm{~J}$ Pearson-Stuttard, ${ }^{2} \mathrm{M}$ Guzman-Castillo, ${ }^{2} \mathrm{~B}$ Collins, ${ }^{2} \mathrm{~S}$ Capewell, ${ }^{2} \mathrm{M}$ O'Flaherty, ${ }^{1} \mathrm{C}$ Millett. ${ }^{1}$ Public Health Policy Evaluation Unit, School of Public Health, Imperial College London, London, UK; ${ }^{2}$ Department of Public Health and Policy, University of Liverpool, Liverpool, UK

\subsection{6/jech-2018-SSMabstracts.42}

Background The UK's decision to exit the European Union will likely affect its current trade regimes. Trade policy can alter food commodity availability and price; it is thus a potentially powerful determinant of food environments and subsequently health. The UK is highly dependent on its fruit and vegetable $(\mathrm{F} \& \mathrm{~V})$ imports. Brexit could therefore affect $\mathrm{F} \& \mathrm{~V}$ price and consumption in the UK. Given the strong association between F\&V intake and cardiovascular disease (CVD), our analysis aimed to quantify the potential effects of F\&V price changes due to Brexit on CVD in English adults between 2020-2030.

Methods We used the previously validated IMPACT Food Policy Model. The model combined publicly available data on F\&V trade, published estimates of UK-specific price elasticities, F\&V intake data from the National Diet and Nutrition Survey, and coronary heart disease (CHD) mortality projections for 2020-2030. We estimated the number of CHD deaths and life-years lost between 2020-2030 among English adults aged 25 years and above as a consequence of five Brexit scenarios: (1) Transitional Brexit; (2) post-Brexit Free Trading Agreement with the EU and maintaining half of the non-EU free trade partners; (3) post-Brexit Free Trading Agreement with the EU but no trade deal with any non-EU countries; (4) post-Brexit liberalised trade regime; (5) no deal Brexit. We then performed Monte-Carlo simulations to better estimate uncertainty of inputs.

Results Under all Brexit scenarios, prices of $\mathrm{F} \& \mathrm{~V}$ are likely to increase on average between $1.8 \%$ and $7.8 \%$. The banana, citrus fruit, and tomato markets are likely to be the most disrupted, with price increases up to approximately $16.7 \%$, $14.3 \%$, and $13.4 \%$ respectively. A transitional Brexit is likely to result in approximately $670 \quad(95 \%$ Uncertainty Interval: 430-980) extra CHD deaths and 6370 (4,360-8,990) lifeyears lost. A liberalised regime which eliminates all import tariffs is likely to contribute approximately 940 (600-1,370) additional CHD deaths and 8870 (6,060-12,540) life-years lost, due to non-tariff trade barriers between the UK and the EU. A no-deal Brexit scenario might be the most harmful, generating approximately $2900 \quad(1,820-4,310)$ extra CHD deaths and $27440(18,200-39,630)$ life-years lost between 2020-2030.

Conclusion This analysis suggested that under all modelled scenarios Brexit is likely to increase the price of $F \& V$ and thus have a detrimental effect on the future diet and health of English adults. The UK government should therefore aim to secure a post-Brexit food system that incentivises the UK population to purchase and consume healthy foods.

\section{OP43 FINANCIAL STRAIN MODIFIES THE ASSOCIATION BETWEEN SYSTEMIC INFLAMMATION AND CARDIOVASCULAR MORTALITY}

\footnotetext{
${ }^{1,2} \mathrm{C}$ Lassale*, ${ }^{3} \mathrm{Al}$ Lazzarino. ${ }^{1}$ Epidemiology and Public Health, University College London, London, UK; ${ }^{2}$ Behavioural Science and Health, University College London, London, UK; ${ }^{3}$ Primary Care and Public Health Sciences, King's College London, London, UK

10.1136/jech-2018-SSMabstracts.43
}

Background Atherosclerosis and cardiovascular disease (CVD) have an inflammatory origin. Moreover, chronic psychosocial stress is associated both with inflammation and CVD. Our aim was to test whether the prognostic value for future CVD risk of a single inflammation test depends on the presence of chronic psychosocial stress.

Methods Data come from the nationally-representative English Longitudinal Study of Ageing. Psychosocial factors (financial strain, depression, social isolation, loneliness) and inflammatory markers (serum fibrinogen and C-reactive protein [CRP]) were collected in 4762 men and women, free of CVD and aged 52 to $101 \mathrm{y}$ at baseline (2004-2005). Cox proportional hazards regression models were fitted to estimate the relationship (hazard ratios [HR] and 95\% confidence intervals) between inflammatory marker and incident CVD death. Interactions terms between fibrinogen and each psychosocial factor were tested. Models were stratified by sex and adjusted for age, smoking, body mass index, physical activity, HDL/total cholesterol, triglycerides, hypertension and diabetes. Added predictive value over conventional CVD risk factors was assessed by change in C-statistics and reclassification.

Results There were 158 CVD deaths during a median followup of $8.1 \mathrm{y}$. The association between both inflammatory markers and CVD mortality was linear: HR $1 \mathrm{~g} / \mathrm{L}$ of fibrinogen $=1.46$; 95\% CI 1.20, 1.78 and HR log-unit $\mathrm{CRP}=1.35$; $1.16,1.57$. Financial strain modified these associations. In the presence of financial strain ( $n=506,24$ deaths), the HRs for fibrinogen $(3.32 ; 1.68,6.57)$ and for CRP $(2.15 ; 1.42,3.26)$ were stronger than in the absence of financial strain $(n=4256$, 134 deaths) (HR fibrinogen 1.33; 1.07, 1.66 and HR CRP 